\title{
Risk of Single Appraisal in Complex Environment: Physical and Perceived Stress in Military Training on Amazon Jungle
}

\author{
Yonel Ricardo de Souza, MD \\ Fabio BiasottoFeitosa, $\mathrm{Dr} P H$
}

\begin{abstract}
The aim of this study was to investigate the correlation between perceived and physical stress in a wearing military training in an environment of Amazon forest.For this, 48 volunteers from the Brazilian Army underwent inventory PSS-14 and blood samples were collected immediately before and at the end of an adaptation to life in the jungle training. Differences and significant positive correlations between all the biochemical variables and between pre and post samples were detected. The mean LDH post and CK post were outside of normal parameters, which points to the manifestation of physical stress during the training. No correlation between perceived stress pre/post and any biochemical variable related to physical stress was found.The results of this study suggest that the perception of control and emotional stability alone cannot be taken into consideration in the management of resources and decision-making in situations of obvious fatigue.

Keywords: physical stress, perceived stress, military, jungle training, fatigue.
\end{abstract}

\section{Introduction}

Stress is an integral part of military training. Basic training is designed to subject the student in various forms of stress, both physical and psychological. The purpose of stress exposure in training is to reproduce a similar real combat situation, so that the military should act in a balanced way under heavy psychological pressure ${ }^{1}$.

The stress caused by training can have negative reactions when the loads imposed are inconsistent with the responsiveness of military, resulting in a psychophysical mismatch with possible negative impact on yield. This inadequacy is associated with physiological, biochemical or psychological changes, which will cause damage to the health of military people ${ }^{2}$.

The biochemical and psychological accompaniments enable quantification of suffering, help the assimilation of training and recovery, promoting health maintenance and monitoring the risk of damage caused by overtraining ${ }^{3}$. Because of this, training monitoring should involve a multivariate appraisal ${ }^{2,4}$,considering that, according toKwaget $a l^{5}$, the somatic and psychological dimensions of stress are interconnected, although independents.

Many direct and indirect methods have been used in the analysis of physical stress resulting from the efforts, which may change during periods of intense training, suggesting a dosage-response ratio ${ }^{6}$. Indirect methods as myoglobin, lactate dehydrogenase (LDH), fragments of myosin heavy chain, aminotranspherases (ALT /AST) and creatine kinase (CK), are most often used. These molecules can be used as markers of skeletal muscle damage due to the fact that they are cytoplasmic enzymes and thus, impermeable by the membrane. Thereby, increased levels of these molecules in the extracellular fluid can indicate a change in permeability or the breaking of the membrane $e^{4,6}$.

Moreover, the rating of performance associated with emotional parameters such stress, fatigue, tension, anxiety, is excellent indicators of physical and mental overload ${ }^{2,7}{ }^{8}$. Many studies have investigated the psychological stress state through the Perceived Stress Scale (PSS-14), created by Cohen et al .

However, studies approaching the correlation between physical and perceived stress are scarce and, in the military environment no studies were found in the scientific literature that have addressed this issue. Therefore, this study aimed to investigate the correlation between perceived and physical stress in a wearing military training on an environment of Amazon jungle, applying the Perceived Stress Scale PSS 14, validated in Brazil by Feitosa ${ }^{10}$, and colleting values of markers alanine aminotranspherase (ALT), aspartate aminotranspherase (AST), creatinekinase (CK) and lactate dehydrogenase (LDH), measured before and after an adaptation to life in the jungle training.

The resultsof this studyadd to the literaturewhenwarn about therisks of usingonly oneassessment toolin complexactivities underpsychological pressure and physical strenuous, such asmilitary profession, firefighters, airline pilots,surgeonsand police, because until now, there no paper that addressed this issue. 
Participants and recruitment

\section{Method}

This study took place in the jungle base of the $54^{\text {th }}$ Jungle Infantry Battalion, in the city of Humaita, Amazon state, Brazil, and was organized by the Laboratory of Interpersonal Relationships and Health, Federal University of Rondonia. The sample consisted of 48 military volunteers (72.9\% males and $27.1 \%$ females), recently moved to the Amazon region, that performed the adaptation to life in the jungle training of Brazilian Army, aged 30.10 years $( \pm 13.74$ years) and able in health inspection carried out by Brazilian army doctors. This study was approved by the Ethics Committee in Research of the Federal University of Rondonia, on December $3^{\text {rd }}, 2013$, protocol number 516.570 .

Psychosocial parameters

The Perceived Stress Scale (PSS 14) was validated in Brazil by Feitosa ${ }^{10}$, it had temporal stability in test-retest $(\mathrm{r}=0.79, \mathrm{p}<0.001)$ and good internal consistency (Alpha $=0.85$ in test and Alpha $=0.86$ in retest), with a mean of $27.3( \pm 7.9)$ in a sample of 128 Brazilian college students ${ }^{10}$. PSS-14 has amplitude of 30 days and features 14 items that must be answered as to the frequency of the item questioned, following a Likert scale (never, rarely, sometimes, often, and very often).

Biochemical parameters

The references values for the concentration of aminotranspherases (ALT/AST) is between 10-37 UI/L and 10-40 UI/L for males and females respectively ${ }^{11}$. The reference value for the concentration of LDH is between 91-150 UI/L, and the references values for the concentration of CK is between 38-174 UI/L and 96-140 $\mathrm{UI} / \mathrm{L}$ for males and females respectively ${ }^{11}$. The unit valueswere quantified by spectrophotometry (reactants) using a Cobas Mira Plus (Roche - USA) equipment.

Statistical analysis

For data analysis the statistical package SPSS version 20.0 was used. Descriptive analyzes and inferences were conducted considering a significance level of $p<0.05$. To verify the relationship between the scores of perceived stress and physical stress (biochemical markers) the correlation Spearman'rho was used. The test of Wilcoxon Signed-Rank was applied to measure the degree of significance between the data obtained before and after the training.

Procedure

First, a lecture was held explaining the dynamics of the study with all participants and military volunteers signed a consent form. Immediately before starting the internship, the military completed the PSS-14 individually and after this a sample of $4 \mathrm{ml}$ of blood was collected from each military, which was centrifuged at 3000 r.p.m. for 5 minutes and cooled between $+2{ }^{\circ}$ and $+8^{\circ}$ Celsius. At the next day the samples were quantified on a specific laboratory. Eight days later, immediately at the end of the training, the same volunteers were gathered and the same blood collections were repeated under the same conditions from the beginning. The PSS-14 inventory was reapplied adapting the same 14 items to the jungle training period ( 8 days).

Primary analyses

\section{Results}

Table I shows the values of mean, median, standard deviation, minimum and maximum limits and percentile distribution in the variables collected:

Table I. Means, medians, standards deviations, limits and percentiles for variables

\begin{tabular}{|c|c|c|c|c|c|c|c|c|c|c|c|}
\hline & & $\begin{array}{l}\text { ALT } \\
\text { Pre }\end{array}$ & $\begin{array}{l}\text { ALT } \\
\text { Post }\end{array}$ & $\begin{array}{l}\text { AST } \\
\text { Pre }\end{array}$ & $\begin{array}{l}\text { AST } \\
\text { Post }\end{array}$ & $\begin{array}{l}\text { CK } \\
\text { Pre }\end{array}$ & $\begin{array}{l}\text { CK } \\
\text { Post }\end{array}$ & $\begin{array}{l}\text { LDH } \\
\text { Pre }\end{array}$ & $\begin{array}{l}\text { LDH } \\
\text { Post }\end{array}$ & $\begin{array}{l}\text { PSS } \\
\text { Pre }\end{array}$ & $\begin{array}{l}\text { PSS } \\
\text { Post }\end{array}$ \\
\hline $\mathrm{N}$ & & 48 & 48 & 48 & 48 & 48 & 48 & 48 & 48 & 48 & 48 \\
\hline \multicolumn{2}{|l|}{ Mean } & 23,33 & 31,23 & 23,89 & 33,56 & 233,70 & 491,37 & 192,92 & 247,96 & 23,45 & 23,35 \\
\hline \multicolumn{2}{|l|}{ Median } & 18,50 & 23,00 & 21,00 & 32,00 & 147,50 & 396,00 & 175,00 & 238,00 & 23,00 & 25,00 \\
\hline \multicolumn{2}{|l|}{ Std.Deviation } & 18,63 & 26,83 & 8,508 & 12,085 & 271,59 & 406,14 & 74,35 & 43,91 & 6,57 & 7,37 \\
\hline \multicolumn{2}{|l|}{ Minimum } & 8,00 & 13,00 & 14,00 & 17,00 & 55,00 & 80,00 & 137,00 & 177,00 & 10,00 & 9,00 \\
\hline \multicolumn{2}{|l|}{ Maximum } & 109,00 & 173,00 & 54,00 & 75,00 & 1651,00 & 2445,00 & 653,00 & 349,00 & 40,00 & 40,00 \\
\hline \multirow[t]{3}{*}{ Percentiles } & 25 & 13,25 & 18,25 & 18,00 & 26,00 & 99,50 & 233,00 & 161,00 & 215,50 & 19,00 & 18,25 \\
\hline & 50 & 18,50 & 23,00 & 21,00 & 32,00 & 147,50 & 396,00 & 175,00 & 238,00 & 23,00 & 25,00 \\
\hline & 75 & 24,75 & 33,50 & 26,75 & 39,00 & 259,00 & 716,00 & 205,75 & 270,25 & 27,50 & 28,75 \\
\hline
\end{tabular}

\section{Correlations}

Table II shows the correlations between the means of the variables collected before the training (pre): 
Table II. Correlations among variables at pre-training

\begin{tabular}{|c|c|c|c|c|c|c|}
\hline & & ALT Pre & AST Pre & CK Pre & LDH Pre & PSS Pre \\
\hline \multirow{2}{*}{$\begin{array}{l}\text { ALT } \\
\text { Pre- Phase }\end{array}$} & CorrelationCoefficient & 1,000 &, $692^{* *}$ & ,279 & ,092 &, 042 \\
\hline & Sig. (2-tailed) & . &, 000 &, 055 &, 536 & ,779 \\
\hline \multirow{2}{*}{$\begin{array}{l}\text { AST } \\
\text { Pre-Phase }\end{array}$} & CorrelationCoefficient &, $692^{* *}$ & 1,000 &, $512^{* * *}$ & $378^{* *}$ &, 110 \\
\hline & Sig. (2-tailed) &, 000 & . &, 000 &, 008 & , 457 \\
\hline \multirow{2}{*}{$\begin{array}{l}\text { CK } \\
\text { Pre-Phase }\end{array}$} & CorrelationCoefficient & ,279 &, $512^{* *}$ & 1,000 &, $418^{* *}$ &, 022 \\
\hline & Sig. (2-tailed) &, 055 & 000 & . & 003 & 881 \\
\hline \multirow{2}{*}{$\begin{array}{l}\text { LDH } \\
\text { Pre-Phase }\end{array}$} & CorrelationCoefficient &, 092 & $378^{* *}$ &, $418^{\text {*** }}$ & 1,000 &, 072 \\
\hline & Sig. (2-tailed) & ,536 &, 008 &, 003 & . & ,629 \\
\hline \multirow{2}{*}{$\begin{array}{l}\text { PSS } \\
\text { Pre-Phase }\end{array}$} & CorrelationCoefficient &, 042 & , 110 &, 022 &, 072 & 1,000 \\
\hline & Sig. (2-tailed) & ,779 & ,457 & ,881 & ,629 & . \\
\hline
\end{tabular}

Significant correlations between ALT/AST, AST/CK and AST/LDH among the indicators of physical stress in the sample collected before the training were observed. No significant correlations between any biochemical and psychological scores among the values collected of samples before the training were identified.

Table III shows the correlations between the means of the independent variables collected immediately at the end of training (post):

Table III. Correlations among variables at post training

\begin{tabular}{|c|c|c|c|c|c|c|}
\hline & & ALT Post & AST Post & CK Post & LDH Post & PSS Post \\
\hline \multirow{2}{*}{$\begin{array}{l}\text { ALT } \\
\text { Post Phase }\end{array}$} & CorrelationCoefficient & 1,000 &, $727^{* *}$ &, $394^{* *}$ & ,264 & ,201 \\
\hline & Sig. (2-tailed) & , &, 000 & ,006 & ,069 &, 170 \\
\hline \multirow{2}{*}{$\begin{array}{l}\text { AST } \\
\text { Post Phase } \\
\end{array}$} & CorrelationCoefficient &, $727^{* * *}$ & 1,000 &, $760^{* *}$ &, $437^{* *}$ &, 041 \\
\hline & Sig. (2-tailed) &, 000 & &, 000 & 002 & ,781 \\
\hline \multirow{2}{*}{$\begin{array}{l}\text { CK } \\
\text { Post Phase }\end{array}$} & CorrelationCoefficient &, $394^{* *}$ &, $760^{* *}$ & 1,000 & $399^{* *}$ &,- 023 \\
\hline & Sig. (2-tailed) &, 006 &, 000 & . &, 005 &, 876 \\
\hline \multirow{2}{*}{$\begin{array}{l}\text { LDH } \\
\text { Post Phase }\end{array}$} & CorrelationCoefficient & ,264 & $437^{* *}$ &, $399^{* *}$ & 1,000 &, 224 \\
\hline & Sig. (2-tailed) & ,069 & ,002 &, 005 & . &, 126 \\
\hline \multirow{2}{*}{$\begin{array}{ll}\text { PSS Post } \\
\text { Phase }\end{array}$} & CorrelationCoefficient & ,201 & ,041 &,- 023 & ,224 & 1,000 \\
\hline & Sig. (2-tailed) &, 170 & ,781 & ,876 & ,126 & . \\
\hline
\end{tabular}

Significant correlations between ALT/AST, ALT/CK, AST/CK, AST/LDH and CK/LDH among the indicators of physical stress in the sample collected immediately after the training were observed. No significant correlations between some biochemical and psychological scores among the values collected of the samples immediately after the training were identified.

Table IV shows the degree of significance between the mean scores obtained before and after the training about each independent variable:

Table IV. Significants between pre and post training within variables

\begin{tabular}{|l|l|l|l|l|l|}
\hline & ALT Pre/Post & AST Pre/Post & CK Pre/Post & LDH Pre/Post & PSS Pre/Post \\
\hline $\mathrm{Z}$ & $-4,215^{*}$ & $-4,901^{*}$ & $-4,990^{*}$ & $-5,334^{*}$ &,$- 154^{*}$ \\
\hline Asymp. Sig. (2-tailed) &, 000 &, 000 &, 000 &, 000 &, 878 \\
\hline
\end{tabular}

*Basedon negative ranks

\section{Discussion}

In the present study, pre and post averages of biochemical markers ALT and AST remained within normal limits (Table I). The pre averages of biochemical markers CK and LDH were already above normal standards. Significant positive correlations between all biochemical markers (Table II and III) and significant differences between all samples pre/post (Table IV) were also detected. The mean LDH and CK showed a positive significant difference pre/post, which indicates to the manifestation of physical stress during the adaptation to life in the jungle training.

According to Baird et $a l^{12}$, assay of CK post indicate lesions in striated skeletal muscle by overloading exercise. Nieoet al $^{13}$ mentioning that significant increases in concentrations of $\mathrm{CK}$ and LDH after training suggest accumulation of fatigue caused by daily exercise and physical unsuitability to it, confirming the risk of muscle injury.

Since there were no physical activities before the training, elevated levels of LDH and CK pre can be explained possibly due to the physical stress caused by acclimatization to hot and humid environment, to which the military recently moved were unseasoned ${ }^{14}$. Lippi et $a l^{15}$ found in their study variations of AST (positive and significant) that accompanied the changes in CK and LDH proportionally, characterizing these markers as efficient in identifying physical damage from overload, on condition that measured are combined. Thus, such 
measures found in this study (.760 to CK and .437 to LDH) indicate the occurrence of physical stress during the internship.

Significant correlation between LDH and CK pre (.418) and post (.399) indicate the occurrence of high training loads in the period covered. According to MacArdleet al ${ }^{16}$, this is justified because the depletion of the anaerobic pathway (ATP-CP) fibers II (intermediate) and R (resistance) occurs through a continuous endurance exercise and subsequent activation of aerobic metabolism by the glycolytic pathway. Enzyme distribution and fiber recruitment is proportional to fiber type in the activity and its predominance ${ }^{17}$. All these concepts underlie our findings, indicating the incidence of physical stress during the training.

The lack of correlation between perceived stress (PSS14) pre or post and either biochemical variable related to physical stress (Table II and III) showed that, in this study, psychological stress behaved completely independent in rate to physical stress. This reinforces the importance of multivariate assessment of stress in its various manifestations (psychological, physical) in a single way ${ }^{18}$ at determining a complex environment as military training.

Moreover, the lack of significant difference between the pre and post readings PSS-14 (Table IV) showed that the military involved in the study were consistent with the psychological preparation of training tasks in the jungle, because even with the occurrence of above normal levels of LDH and CK Post (Table I) they completed training with levels of perceived stress below the mean reference value used.Although this result is one of the psychological goals suggested by Wilcox ${ }^{19}$ in basic military training, this study points out to a danger of damage to the physical integrity of the military. The finding suggests that the assessment of risk to physical integrity in practice situation in the jungle made by biochemical markers of stress is safer than assessment by perceived stress. The military may be psychologically fit to continue a physical task even when your body has exceeded the safety limits of physical stress.

Limitations

Some intervening variables may have affected the results, like the fact of the high temperature and humidity of the Amazon rainforest and its influence, especially in the military study, recently presented and not acclimated. Sawka et al (2011) describe diverse influences of heat and humidity to psychological and physical stress. Furthermore, the sample size $(\mathrm{N}=48)$ not grounds a reliable reproduction of the phenomenon in similar situations.

Future directions

As to physical stress during military training, there are gaps in the studies that address other markers such as cortisol (salivary and plasma) or mineral (calcium and magnesium). Psychology has other instruments to assess mood, anxiety, resilience and coping, which should be useful in situations of strong psychological pressure, as studied.

\section{Conclusions}

The perception of control and emotional stability cannot be taken into account as isolated in the management of resources, especially human, and decision making in situations of obvious exhaustion, because the discrepancy between serum levels of stress and your perception can lead the military or their superiors/subordinates to believe that the limits of the body are still extensive. Several aspects must be considered when dealing with stress in the military environment.

\section{References}

[1]. Moore BA, Crow BC. Assessment and management of acute combat stress on battlefield. ON: Military Psychology: Clinical and Operational Applications. 2nd ed. New York: Guilford Press; 2012.

[2]. Kellman M. Preventing overtraining in athletes in high-intensity sports and stress/recovery monitoring. Scandinavian Journal of Medicine \& Science in Sports. 2010;20(2):95-102.

[3]. Rehm KE, Elci OU, Hahn K, Marshall Jr GD. The impact of self-reported psychological stress levels on changes to peripheral blood immune biomarkers in recreational marathon runners during training and recovery. Neuroimmunomodulation. 2013;20(3):164-176.

[4]. Jürimäe J, Mäestu J, Jürimäe T, Mangus B, Duvillard SP. Peripheral signals of energy homeostasis as possible markers of training stress in athletes: a review. Metabolism. 2011;60(3):335-350.

[5]. Kwag KH, Martin P, Russell D, Franke W, Kohut M. The impact of perceived stress, social support, and home-based physical activity on mental health among older adults. The International Journal of Aging and Human Development. 2011;72(2):137-154.

[6]. Finsterer J. Biomarkers of peripheral muscle fatigue during exercise. MusculoskeletalDisorders. 2012;13(218):1-13.

[7]. Morgan AL, Tobar DA, Snyder L. Walking toward a new me: the impact of prescribed walking 10,000 steps/day on physical and psychological well-being. Journal of Physical Activity \& Health. 2010;7(3):299-307.

[8]. Campbell J, Ehlert U. Acute psychosocial stress: does the emotional stress response correspond with physiological responses?.Psychoneuroendocrinology. 2012;37(8):1111-1134.

[9]. Cohen S, Karmack T, Mermelsteinm RA. Global measure of perceived stress. Journal Health SocietyBehavio. 1983;24(4):385-396.

[10]. Feitosa FB. Escala de Estresse Percebido (PSS-14-BR)/Contribuições para a adaptação da Perceived Stress Scale à realidade brasileira. Projeto Suporte social e habilidades sociais na qualidade de vida. 2012; process no. 470954/2009-4.

[11]. Talaska F, Marshall F, Dunning B. A Manual of Laboratory and Diagnostic Tests. Philadelphia: Lippincott Williams and Wilkins Copyright, 2009. 
[12]. Baird MF, Scott M, Graham JS, Baker, GFB. Creatine-kinase- and exercise-related muscle damage implications for muscle performance and recovery. Journal of Nutrition and Metabolism. 2012;20:1-13.

[13]. Nie J, Tong TK, George K, Fu FH, Lin H, Shi, Q. Resting and post-exercise serum biomarkers of cardiac and skeletal muscle damage in adolescent runners. Scandinavian Journal of Medicine \& Science in Sports.2011;21(5):625-629.

[14]. Sawka MN, Leon LR, Montain SJ, Sonna, LA. Integrated physiological mechanisms of exercise performance, adaptation, and maladaptation to heat stress. Comprehensive Physiology. 2011;1:1883-1928.

[15]. Lippi G, Schena F, Salvagno GL, Montagnana M, Gelati M, Tarperi C, Banfi G,. GuidiGC. Acute variation of biochemical markers of muscle damage following a $21-\mathrm{km}$, half-marathon run. Scandinavian Journal of Clinical \& LaboratoryInvestigation. 2008;68(7):667-672.

[16]. McArdle WD, Katch FI, Katch VL. Exercise Physiology: Nutrition, Energy, and Human Performance. Philadelphia: Lippincott Williams \& Wilkins Copyright, 2010.

[17]. Kwak HB. Exercise and obesity-induced insulin resistance in skeletal muscle. Integrative Medicine Research.2013;2(4):131-138.

[18]. Juster RP, McEwen BS, Lupien SJ.Allostatic load biomarkers of chronic stress and impact on health and cognition. Neuroscience \&Biobehavioral Reviews.2010;35(1):2-16.

[19]. Wilcox VL. Burnout In Military Personnel. ON: Military Psychiatry: Preparing in Peace for War. Washington DC: Government Printing Office, 2000. 